\title{
PUTTING PROCESS INTO ROUTINE ACTIVITY THEORY: VARIATIONS IN THE CONTROL OF CRIME OPPORTUNITIES
}

\author{
Lacey Schaefer ${ }^{1}$ \\ Lorraine Mazerolle ${ }^{2}$ \\ ${ }^{1}$ School of Criminology and Criminal Justice, Griffith University \\ ${ }^{2}$ Institute for Social Science Research, University of Queensland
}

Submitted to the Security Journal

September 2015

Correspondence addressing this article should be directed to: Lacey Schaefer, School of Criminology and Criminal Justice, Griffith University, Social Sciences Building (M.10), office 3.01G, 176 Messines Ridge Road, Mt Gravatt QLD 4122 Australia; phone: +61 073735 3482; email: l.schaefer@griffith.edu.au.

Acknowledgements: The fellowship scholarship, research undertaken and data used in this paper was supported by three Australian Research Council grants including the Centre of Excellence Grant (CEPS) (RO700002) to Mazerolle, the Discovery Grant (DP1093960) to Cherney and Murphy and Discovery Grant (DP1094589) to Wickes. We gratefully acknowledge all contributors to the ACCS (see www.uq.edu.au/accs) and crime data from the Queensland Police Service. 


\begin{abstract}
This paper extends the basic tenets of routine activity theory by explicating three unique mechanisms that influence crime prevention actions: relationality, relativity, and responsibility. We assess how macro variations in crime opportunities influence the social processes associated with readiness for three crime control actions: offender handling, target guarding, and place managing. We explore the utility of these theoretical advancements using multilevel survey data from the Australian Community Capacity Study (ACCS) that includes 4390 residents across 148 suburbs in the Greater City of Brisbane. Incorporating individual measures of perceptions of routine activity dynamics and community-level measures of social structure, we use multilevel mixed-effects ordinal logistic regression to explain variations in the three different crime control actions. We find moderate support that some social processes are more strongly paired with some types of crime control actions than others: relationality most strongly predicts offender handling, relativity is most significantly associated with target guarding, and responsibility is most influential for place managing. We argue that the routine activities of crime can be better understood by delineating the social processes of crime prevention, and that these should be modeled on a continuum and considered in context of community variations in social structures.
\end{abstract}

Keywords: Routine activity theory, crime prevention, crime control, opportunity theory, guardianship, place management 
Routine activity theory (RAT) was originally proposed as a sociological explanation of trends in the availability of crime opportunities nearly 40 years ago (see Cohen and Felson 1979). From the outset, RAT offered a perspective focused on crime events (rather than criminal propensities), and evolved over time to provide pragmatic solutions to crime problems. Currently, an extensive literature on RAT demonstrates how the three crime control actions of RAT - offender handling, target guarding, and place managing (Cohen and Felson 1979; Cornish and Clarke 2003; Eck, 1994, 2003; Eck and Weisburd 1995; Ekblom 2005; Felson 1986; Felson 1995; Osgood et al. 1996; Reynald 2011a; Sousa and Kelling 2006; Weisburd and Eck 2004; Wortley 2001) - can reduce crime events.

Oftentimes, the three crime control actions of RAT are considered as either present or absent: offender handlers either handle or they don’t, target guardians either guard or they don't, and place managers either manage or they don’t. Felson (1995) describes four levels of accountability (personal, assigned, diffuse job, and general) for handlers, guardians, and managers, yet RAT has not properly addressed how social processes might influence the degree to which these three crime control actions vary for different types of crime opportunities.

In this paper we argue that three distinct social processes differentiate and distinguish both the form and degree of the three crime control actions. First, we suggest that handlers vary in their relationality with potentially motivated offenders which influences their ability to discourage the pursuit of crime opportunities. Second, we propose that guardians vary in their relativity to suitable targets or victims which shapes their capacity to enhance the risks that accompany existing crime opportunities. Third, we argue that managers vary in their responsibility for places which influences their willingness to reduce the availability of crime opportunities.

We use multilevel survey data from the Australian Community Capacity Study (ACCS) to explore distinctions between these three unique mechanisms - what we call the 
“3Rs" - and their influence on the three crime control actions. This paper begins with an overview of how RAT has progressed over time as an opportunity-focused explanation for crime. In particular, we demonstrate how routine activity theory transitioned from a sociological account of different opportunity structures to event-based models that explain how variations in different ingredients of crime create different crime opportunities. Next, we highlight the differences between crime control actions, drawing attention to the specific linkage between the intervener and the crime opportunity. Third, we propose that three different processes - relativity, relationality, and responsibility - influence the different crime control actions of handling, guarding, and managing. We reason that these mechanisms of crime control are conditioned by characteristics of the individual actor and the community context in which he or she is embedded. We suggest that a person's experiences and surroundings create routine activity dynamics that then prompt or hinder crime control action. We test these theoretical speculations using the ACCS data and show that the 3R processes work in somewhat different ways to help control different crime problems, concluding with a call for refinements to RAT.

\section{THEORETICAL FRAMEWORK}

\section{THE EVOLUTION OF ROUTINE ACTIVITY THEORY}

The introduction of routine activity theory in 1979 prompted a marked shift in the core components of criminological theory. Until this time, dominant theories of crime offered explanations for criminal propensity, assuming that the crime event itself was the natural manifestation of an offender’s criminogenic makeup (Lilly, Cullen, and Ball 2007). The transition away from theories of offender motivation birthed new scholarship that explored the causes and consequences of crime opportunities, showing that criminals cannot commit crime absent the chance to do so (Clarke 2008; Felson and Clarke 2008). Opportunity theories 
provided a pragmatic solution to crime prevention, concluding that a reduction in offending can be created by reducing one or more elements of the crime event (Felson and Clarke 1998).

Opportunity theorists are consistent in their use of this logic, yet varied in their points of theoretical emphasis. For example, routine activity theory started as a sociological explanation of trends in the availability of crime opportunities (Cohen and Felson 1979), then shifted to explain opportunity variations in victimization (Garofalo, Siegel, and Laub 1987; Lynch 1987; Mustaine and Tewksbury 1999), and has since developed into policing and behavioral frameworks that draw attention to the exploitation and control of those opportunities (Cornish and Clarke 2003; Eck and Clark, 2003; Ekblom 2005; Felson 1995; Groff 2007; Reynald 2011a; Sherman, Gartin, and Buerger 1989; Wortley 2001). As opportunity theories advanced, we see variations in the level of analysis (from macro to micro), the ingredients of the crime event (from general guardianship to specific agents and roles), and the attracted audience (from sociologists to psychologists and from city planners to police officers; Clarke, 2012). We suggest that in this progression of RAT, the link between individual behaviors being conditioned by larger social processes - as initially stipulated by RAT - has been somewhat lost. The original manifestation of RAT (see Cohen and Felson, 1979) showed that structural dynamics impact target attractiveness or guardian availability. These structural dynamics are now often neglected in contemporary RAT studies, which focus instead on if the victim or guardian is present rather than how the convergence of opportunities are manifested. Contemporary use of routine activity theory, therefore, has moved away from complex interactions and toward dichotomies about the presence or absence of elements of crime event. These differences in the waves of RAT scholarship as we see them are depicted graphically in Figure 1; each of these formulations is detailed below.

First-Wave Routine Activity Theory 
As seen in Figure 1a, the components that are commonly referenced from Cohen and Felson's (1979) original stipulation of routine activity theory are a motivated offender and suitable target coming together in space and time in the absence of a capable guardian; these are the ingredients that are minimally necessary for a crime to occur. From this beginning, routine activity theory is often used as a binary framework, such as the occurrence or prevention of a crime due to the presence or absence of a guardian. Less popularly cited from the initial study is the macro-sociological approach assumed by the authors. In its original form, routine activity theory links crime rates to changes in social structural conditions (such as trends in individual patterns of activity due to sociodemographic changes in labor force participation). Cohen and Felson's analyses employed longitudinal aggregate data to demonstrate how "the structure of the community may affect the tempo" of the activities contained therein (1979:605). Their concern with macro-level circumstances is oft neglected, despite the causal influences these structures have in producing the routine behaviors that consequentially create or block opportunities for offending and guardianship. We suggest that this inattention to the larger context of crime opportunities has shifted routine activity theory toward explanations of individual crime events, drawing focus away from the social milieus that facilitate the divergence or convergence of the elements of crime.

\section{Second-Wave Routine Activity Theory}

The subsequent wave of routine activity theory studies (depicted in Figure 1b) adopted an outcome orientation focused on individual crime events. Observed primarily in situational crime prevention research, the crime triangle outlines the organization of elements present and/or absent during a crime event (or a missed crime event, as the case may be). Whether through defensible space (Newman 1972), crime prevention through environmental design (Jeffery 1971), or problem-oriented policing (Clarke and Eck 2005; Goldstein 1979, 1990), police and crime prevention practitioners focused on creating or manipulating settings 
so that the efforts and risks of crime were enhanced and the rewards of crime could be reduced as perceived by prospective offenders (Cornish and Clarke 1986).

In the original articulation of RAT, researchers demonstrated how crime opportunities could be exploited when three conditions merge; yet the second wave of RAT studies tended to reverse this emphasis and focus on how avoidance of a crime event comes from adding controllers who can influence these conditions. These controllers include handlers for offenders, guardians for targets or victims, and managers for places (Eck 1994; Felson 1986, 1995). While scholars focused on the application of crime discouragement techniques (Clarke 1992; Felson 1995), an implied theoretical importance to Eck’s (1994) crime triangle triplet pairings emerged: That the presence (or absence) of different types of crime control, in whatever form, can disrupt the development, maintenance, or pursuit of crime opportunities. The crime triangle is now widely adopted as a heuristic that conveys (1) that the removal of one of the sides of the inner triangle will prevent a crime, and (2) that the addition of one of the sides of the outer triangle will prevent a crime; conversely stated, (3) the convergence of all three sides of the inner triangle will lead to a crime event, but (4) the absence of one of the sides of the outer triangle can likewise allow a crime to occur. Conceptualized in this way, we suggest that the crime triangle encourages dichotomized thinking: A triangle side is present or absent, and thusly, a crime occurs or is prevented. This transition toward a focus on crime events minimized concern about the context or catalysts of crime control and emphasizes the specific crime prevention approaches that ask "if” (rather than "how") offenses were deterred.

Beyond this general trend, a handful of studies exist that go beyond these binary contingencies. Nick Tilley and his United Kingdom-based colleagues, for example, draw attention to "the mechanisms through which preventive outcomes are achieved, the means of their activation and the contexts needed for these preventive processes to operate” (2009:4). These scholars suggest that crime is not merely a consequence of coincident changes to 
offenders, targets, and guardians; rather, they suggest that changes in crime opportunities are the result of specific and strong preventative measures being purposively implemented (Farrell, Phillips, and Pease 1995; Farrell and Pease 2007). Overall, we suggest that these situational crime prevention studies succeed in resolving "why" a crime event occurs or is avoided (Ekblom 1994; Farrell et al. 1995; Tseloni et al. 2004), yet fall short of detailing the social context and granularity of crime prevention actions.

These adaptations of RAT are lacking in several ways. First, scholars may identify that a crime hotspot is ripe for offending because place managers are absent; however, while this informs us why crimes occur there, we still lack information about how the situation developed (i.e., why there are no controllers present, why they fail to act, or why their actions are not effective). Here we see that the triggering factors are recognized, yet the processes or development of those same triggers are not well understood (Pawson and Tilley 1997). Second, research in the second wave of RAT emphasized the symptoms rather than the causes of crime, and thus focused on reducing crime opportunities by blocking the mechanism that catalyzed the event (Laycock and Tilley 1995; Tilley 1993). By neglecting the cause of crime as a consequence of focusing on the symptoms of crime, many of the catalyzing conditions of crime are overlooked; resultantly, many opportunities to ameliorate crime problems are bypassed.

\section{Third-Wave Routine Activity Theory}

Given the importance of crime controllers, the most recent progression of routine activity theory (portrayed in Figure 1c) explores the characteristics of guardianship that influence crime (Hollis-Peel, Reynald, and Welsh 2012; Reynald 2009, 2010, 2011a, 2011b). This body of research sought to uncover the steps involved that lead to the prevention of crime via capable guardianship. Moving away from the coupling of offenders, targets, and places with their respective controllers, this recent RAT research restored the concept of 
guardianship as “the physical or symbolic presence of an individual (or group of individuals) that acts (either intentionally or passively) to deter a potential criminal event” (Hollis-Peel et al. 2011:54). Rather than isolating guardians to their association with potential targets and victims, this group of scholars envisions guardians as anybody and everybody on the scene of a possible crime who is available, monitors the situation, and intervenes when necessary (Reynald, 2011a). This body of scholarship highlights the importance of inadvertent and occasional intervention whereby crimes are deterred often without the cognizance or will of the guardian. Thus, as with earlier iterations of RAT, the mere presence (or suggested attendance) of a person may be sufficient to disrupt the lead-up to crime. This group of scholars envisages the unfolding of guardianship: the prospective crime controller must first be present, must then be looking out for crime, and then must take action. Although this tripartite conceptualization of guardianship is more processual in nature than the "yes/no" sides of the crime triangle, we are still left with isolated binary steps (e.g., Is a guardian present? If yes: Did the guardian monitor? If no: Crime occurs). Again, then, these studies frequently neglect the processes that facilitate that crime control, whether it be the lead-up to availability, monitoring, or intervention.

\section{A Proposed Fourth-Wave Routine Activity Theory}

Building on past RAT scholarship, we propose that the social processes that facilitate crime controller behaviors are underdeveloped in the crime opportunity literature.

Accordingly, we extend the extant theoretical understanding of RAT (illustrated in Figure 1d) that both recognizes the three waves of RAT development, and, at the same time, makes explicit the catalysts and granularity of the processes that influence variability in these crime control behaviors. We speculate that there are different forms and gradations of social processes that ready individuals for specific types of action, which we explore in this paper. Conversely, we propose that these different processes not only activate some crime control 
actions, but can also hinder other crime control actors from intervening. As such our study seeks to uncover the underlying processes that encourage (or inhibit) degrees of handling, guarding, and managing. We outline these theoretical speculations - different types of crime control action and the dynamic processes by which they unfold - in the two sections that follow.

\section{VARIATION IN CRIME CONTROLLER ACTION}

In this paper we argue that there are different forms of action a crime controller could take to prevent a crime event from developing or being exploited. Not an entirely new concept, two branches of criminological research already identify the associations between crime control mechanisms and varying outcomes. First, a number of studies examine the routes of action that people and agencies take toward controlling crime. We know that there is variation between formal and informal social control (Bursik and Grasmick 1993; Lambert et al. 2011; Sampson 1986), between direct and indirect paths to crime discouragement (Bernburg and Krohn 2003; Rankin and Wells 1990; Wells and Rankin 1988), between willful and accidental crime prevention (Felson 1995; Hollis-Peel et al. 2011), and between private and public interventions (Bursik 1999, 2000; Warner 2007; Wilkinson 2007).

The second branch of criminological research linking crime control motivations and crime control outcomes revolves around the myriad of techniques of situational crime prevention, categorized according to different intended goals. There are, for example, differences between actions that increase the effort (Lasley 1998), increase the risks (Hunter and Jeffery 1997; Painter and Tilley 1999), reduce the rewards (Clarke and Mayhew 1998; Sloan-Howitt and Kelling 1992), reduce provocations (La Vigne 1994), and remove excuses (Shearing and Stenning 1992) for crime (all of which are even further subdivided; Clarke 1997; Clarke and Eck 2005; Wortley 2001). Taken together, these techniques help to "estimate in a preliminary way what their impact is likely to be overall, and in relation to 
particular types of crime problems” (Cornish and Clarke 2003:89). Indeed, crime disruption initiatives acknowledge that there are different kinds of crime problems, and that solutions must be tailored to prevent the merging of the identified crime-causing conditions.

In the problem-oriented policing literature and its offshoots, each crime controller (handlers, guardians, and managers) is paired with an element of the crime event (offenders, targets/victims, and places, respectively; Clarke and Eck 2005; Eck 1994; Felson 1995, 2008; see also Sampson, Eck, and Dunham 2010). Yet while these dyads link together the crime controller and the element of the crime event, criminologists have not proposed a theory of how each of these pairings differ in reducing crime. The processes that activate the crime control actions are not well understood either as a dichotomous condition (present or absent) or, as we will argue, on a continuum.

Here we hypothesize that the key difference between different types of crime control is how each impacts crime opportunities. We propose three ways that crime controller and crime event element pairings impact crime opportunities; these processes are presented as a typology in Figure 2. The right-most column of the figure shows how the three types of crime controllers each work through one particular element of a crime event to variably alter emerging or existing chances for offenders to unite with targets. While some forms of action may have multiple outcomes (for example, one behavior might guard a target and also manage a place, hence the desire to lump crime control actions together as "guardianship”), we argue that the underlying process of crime disruption is different. First, handlers take some degree of action with offenders in order to minimize the pursuit of crime opportunities. Handling does not involve manipulating the real environment, but rather relies on social arrangements (existing or manufactured) that make the offender less likely to take advantage of chances to commit crime that are already available. Second, guardians take some degree of action with suitable targets and victims in order to enhance the risks that accompany existing crime opportunities. Guarding does not get rid of a crime opportunity altogether, but 
simply makes it less attractive for a motivated offender. Third, managers take some degree of action with places (physical or virtual) in order to reduce the availability of crime opportunities. Managing involves making the environment less conducive to crime, working to eliminate chances to offend.

Often, criminologists and crime prevention practitioners use target guarding and place managing terms interchangeably, or are unclear on the precise role of each (see Hollis-Peel et al. 2011; Wilcox, Madensen, and Tillyer 2007). One reason for this is that a single crime control action (such as a resident locking their front door) is traditionally seen as both guardianship and management. This confusion may be caused by an inclination to see spaces as being in the physical realm only (e.g., a car, a city block, a store), which is exacerbated by the idea of ownership or obligation of care (e.g., the degree to which a supervisor really organizes the activities that occur in that place). Yet there are more abstract conceptualizations of place that must be considered, as a non-physical space for which no person is directly responsible can promote or prevent crime. Seen in this light, the difference between target guarding and place managing refers back to what the goal of the crime control action is; is the actor trying to make a crime opportunity unattractive or make the crime opportunity unavailable? We argue that actions that alter crime opportunities that are already present in the environment constitute target guardianship, while actions that reduce the existence of crime opportunities constitute place management.

As such, our typology depicted in Figure 2 outlines three distinct crime control outcomes: (1) Offender handlers prevent a person from pursuing a chance to commit crime, (2) Target guardians block people from committing crime when the chance is there, and (3) Place managers restructure the environment (physical and virtual) so that there are fewer chances for offenders to commit crime. We argue that any individual can be any of these crime controllers at any given time in any given place (and indeed, most people are handlers, guardians, and managers at different times and at different places, all in one day); the 
embodiment of these roles is fluid, and thus draws back to the causal link between the crime control actor and the impact on the crime opportunity for that element of the crime event. This typology hypothesizes that there are differences between crime controllers and the impact on crime opportunities. This then also leads us to assert that there are differences within these linkages.

\section{PROCESSES OF CRIME CONTROL}

Collective processes of crime control are well understood in the contemporary generation of communities and crime literature. These studies explore individuals’ willingness (and a neighborhood's capacity) to intervene in different types of communities and problems and across a range of outcomes (Browning, Feinberg, and Dietz 2004; Morenoff et al. 2001; Reynald 2010, 2011b; Sampson 2008; Sampson, Morenoff, and Earls 1999; Sampson, Raundenbush, and Earls 1997; Warne, 2007; Wilkinson 2007). These studies, however, often rely on a dichotomized outcome: Did the person intervene? Was the crime prevented? Yes or no. Yet we argue that important dynamic processes influence whether or why a potential crime controller disrupts the meeting of the necessary ingredients for crime (as well as when and how that action occurs). Referring back to Figure 1d and Figure 2, we propose that a set of three "routine activity dynamics" - labeled in this paper as the "3Rs" - help to shape the action a crime controller does or does not take toward the respective element of the crime event. We ask: What influences the degree (if any) that the prospective handler actually handles, the potential guardian actually guards, and the possible manager actually manages?

First, handlers vary in their relationality with motivated offenders to minimize the pursuit of existing crime opportunities. Relationality refers to a dynamic state of social integration that shapes how people relate to one another. Criminology has long recognized the role of interpersonal relationships in preventing or encouraging crime. From the 
perspective of the offender, social bond theory (Hirschi 1969), differential association theory (Sutherland 1947; see also Akers 1998), and social support theory (Cullen 1994) all acknowledge the impact of social relationships. More recently, criminologists have examined the community-level crime prevention effects of social ties (Ross and Jang 2000; Sampson, Morenoff, and Gannon-Rowley 2002; Taylor et al. 1984; Warner 2003), uncovering that a neighborhood's level of collective efficacy (Morenoff et al. 2001; Sampson et al. 1997) is influenced by the arrangement of resident networks (Bellair 1997; Browning 2009; Browning et al. 2004; Mazerolle, Wickes, and McBroom 2010; Pattillo 1998; Warner 2007; Warner and Wilcox Rountree 1997; Wickes et al. 2013; Wilkinson 2007). Community relationships facilitate shared expectations for behavior and crime control, thereby enhancing the capacity for intervention when necessary. Offender handling often takes places through a "web of informal crime control” (Felson 1986:122), which highlights the importance of relationality in limiting prospective offenders’ pursuit of available chances to commit crime.

Second, guardians vary in their relativity to suitable targets/victims to enhance the risks that accompany existing crime opportunities. Relativity refers to the level of connectivity of a person in his or her daily situations. The more closely or intimately an individual is situated relative to the pulse of neighborhood life the more likely a person will observe deviant behavior (Cohen and Felson 1979; Tseloni et al. 2004; Xie and McDowall 2008). Neighborhood attachment fosters attitudes that catalyze a concern for community wellbeing, which can have both direct and indirect effects on crime prevention (Brown, Perkins, and Brown 2004). This feeling of relative connectedness enhances social cohesion, which can provide the impetus to intervene (Goudriaan, Wittebrood, and Nieuwbeerta 2006; Hirschfield and Bowers 1997; Morenoff et al. 2001; Sampson and Groves 1989). We argue that a person's connection to his or her community will impact the perception of crime opportunities and problems (existing and developing), knowledge about available remedies, 
and assessments of benefits and risks of intervening. In turn, a person's connectivity to his or her home community is predicted to impact guardianship behaviors.

Third, managers vary in their responsibility for places to reduce the availability of crime opportunities. Responsibility refers to a sense of duty to contribute to the welfare of some space. Community participation and civic engagement create direct and indirect crime prevention effects, producing behaviors that address incivilities and enhance a neighborhood's wellbeing (Brown et al. 2004; Kelling and Wilson 1982; Perkins et al. 1990). In order for crime opportunities in the community to be effectively limited, residents must care to address them; care suggests community accountability, among individual residents and collectively. A person's sense of responsibility, then, is expected to influence community conditions and stymie the development of crime opportunities.

We refer to these “3Rs” as routine activity dynamics. These 3Rs (relationality, relativity, and responsibility) are embedded in both the macro and micro processes that facilitate crime control action (Felson 2008). Accordingly, our extended explication of RAT also pays attention to the macro-social context that was foundational to RAT from the beginning (Cohen and Felson 1979). We reason that social contexts orchestrate the association between actors (offenders, victims, and crime controllers) and their behaviors (Weisburd 2012). We argue, therefore, that the nature of an actor's relationality with others, their relativity with their surroundings, and their responsibility for their space are also influenced by the social structures of their immediate community. This is certainly not to say that an individual only takes crime control action in their own neighborhood; rather, we suggest that the characteristics of a person's residential area have consequences for the 3Rs that catalyze handling, guarding, and managing. Although we suggest that relationality, relativity, and responsibility are dynamic, we adopt the original notions of RAT that these social processes become routine due to the structural conditions of neighborhoods, and may be more or less effective as crime control causes within certain community contexts. 
Thus, overall, we approach RAT in this paper as a multilevel and multidimensional process: People engage with their environments based on their experiences and expectations, both of which are conditioned by the larger social setting. Because individual crime controllers are embedded in communities, the reciprocating associations between the actor and their neighborhood will dynamically impact crime prevention (Reynald 2011b; Sampson et al. 1997; van Wilsem, Wittebrood, and de Graaf 2006; Wilcox and Land 1996; Wilcox et al. 2007). As an illustrative example, we can imagine an individual failing to intervene in an ongoing offense because he or she lives in a high-crime neighborhood and fears personal victimization or has come to view the crime as normative; in this instance, the community conditions have prompted the individual's inaction, but that inaction has symbiotically contributed to those same community conditions (i.e., more crime). Thus, returning to the initial understanding of RAT, we speculate that the structure of a community helps shape the dynamic social processes that influence how crime opportunities are responded to (that is, the degree to which residents engage in varying forms of crime control action). As a consequence, we test the hypothesis that the 3Rs variably impact different forms of crime control action whilst also acknowledging the role of individual and community characteristics in shaping these interrelationships.

\section{METHOD}

In this paper, we use multilevel survey data from the Australian Community Capacity Study (ACCS) to better understand variations in the control of crime opportunities. We categorize crime control actions and specify the social processes that influence the development of each. We have hypothesized that (1) relationality impacts handling to reduce offenders’ pursuit of crime opportunities, (2) relativity impacts guarding to make existing targets and victims less attractive, and (3) responsibility impacts managing to reduce the crime opportunities that are available. Although the routine activity dynamics that we 
identify may be relevant for any type of crime control action, we propose that these processes differentially accommodate the unfolding pathways toward different forms of crime control. The relevance of individual factors and community characteristics in influencing these processes and predicting action are also recognized, therefore these contextual considerations are included in our statistical models.

\section{AUSTRALIAN COMMUNITY CAPACITY STUDY AND SAMPLE}

Our paper draws on data collected through the Australian Community Capacity Study (ACCS), a longitudinal community survey of the processes associated with crime and disorder. In this paper, we use data from the third wave of the ACCS, gathered through computer-aided telephone interviews with Brisbane residents in 2010 (Mazerolle et al. 2012). Over 4,000 survey participants answered questions about informal social control, community attachment and engagement, perceptions of police and government, and community problems. This is supplemented by census data from the Australian Bureau of Statistics and crime data from the Queensland Police Service. More detail about the methodology of the ACCS can be found in the technical report for the project (Mazerolle et al. 2012).

The ACCS is a hierarchically nested survey, using a three-stage sampling design (see Mazerolle et al. 2012). First, the 148 suburbs sampled in this third wave correspond with neighborhoods selected for previous waves of the survey, which were purposefully chosen according to land use characteristics and adjacent suburb qualities. Second, the study used a purposive sampling strategy that incorporates a quota scheme to determine the number of residents to be surveyed from within each suburb; this was accomplished using power analysis software for multilevel samples (Raudenbush et al. 2011). Third, participants were carefully drawn from the suburbs selected for the ACCS survey. For the Brisbane sample, $51 \%$ of respondents were sampled from previous waves of the ACCS project, while the remaining 49\% were selected using random-digit dialing. The consent and survey 
completion rate for the Brisbane sample was $68.5 \%$. The final sample of the third wave of the ACCS includes 4,390 individual respondents from 148 neighborhoods, with the number of survey participants from within each suburb ranging from 12 to $67(M=30, S D=9.05)$.

\section{VARIABLES}

The current study tests the hypothesis that different social processes are responsible for different forms of crime controller actions. Moreover, we predict that these intervention behaviors will be conditioned by individual and community characteristics. The following subsections describe the variables from the ACCS survey used to examine these relationships.

\section{Dependent Variables: Crime Controller Actions}

The outcomes of interest are the actions that individuals may take to control crime opportunities in their neighborhood. As discussed in the review of literature, we propose that there are different forms of behaviors corresponding with the actor and their association to the crime opportunity and element of the crime event (refer to Figure 2): offender handling occurs when the individual minimizes someone's pursuit of existing crime opportunities, target guarding occurs when the individual enhances the risks that accompany existing crime opportunities, and place managing occurs when the individual reduces the availability of crime opportunities. The ACCS survey asks respondents about their neighbors' likelihood of intervening in a list of prospective crime problems (on a scale from $1=$ very unlikely through $5=$ very likely). These questions reflect one component of collective efficacy (Sampson et al. 1997), and were intentionally designed as ecometric measures. Prompting respondents to reflect about how members of their community would be likely to act has distinct benefits for the test of our hypotheses in this paper. We suggest that study participants are likely projecting their own understandings of accountability and action orientations onto others in their community. As a consequence, a community’s likelihood of intervening can be understood as a collective representation of individual reflections about crime control actions. 
Within the ACCS, survey respondents were prompted to estimate the likelihood of intervention among residents in their community for a variety of issues. We selected crime problems that operationalized our proposed theory of handling, guarding, and managing (with each scale ranging from 1 to 5), and ensured that these items were not strongly statistically associated $\left(\alpha=.451 ; r_{\mathrm{s}}{ }^{\mathrm{OH} * \mathrm{TG}}=.243 ; r_{\mathrm{s}}{ }^{\mathrm{OH}^{*} \mathrm{PM}}=.222 ; r_{\mathrm{s}}^{\mathrm{TG} * \mathrm{PM}}=.231\right)$. Offender handling is composed of the estimated community likelihood of intervening "if a group of children were skipping school and hanging around on a street corner” $(M=3.28, S D=1.33)$; this selected variable reflects how handlers influence prospective offenders' access to or pursuit of possible chances to commit crime. Target guarding represents the community's likelihood of intervening "if somebody was getting mugged" $(M=4.00, S D=.95)$; this item mirrors the concept that guardians adjust risks for offenders that engage with crime opportunities. Place managing corresponds with the projected community likelihood of intervening "if a new legal brothel was being planned in your community” $(M=4.09, S D=1.09)$; this measure indicates how managers disrupt the development of crime opportunities. Each of these crime problems was thoughtfully selected for each crime control behavior, chosen based on our hypothesized typology of how the actor engages with the crime opportunity (see Figure 2): by controlling access to (i.e., offender handling), by adjusting risks of (i.e., target guarding), or by reducing the existence of (i.e., place managing) opportunities for offending. Importantly, we utilize variables with an ordinal level of measurement. Rather than asking respondents about crime control action in a binary way, here we are tapping into the graded likelihood of intervention that is integral to our thesis: That crime control is dynamic, not dichotomous.

\section{Routine Activity Dynamics}

The central goal of the present paper is to examine the gradient contributions of varying social processes - the 3Rs - that are associated with different crime control behaviors. We theorize that three processes influence crime control action: offender handling 
varies according to relationality, target guarding according to relativity, and place managing to responsibility. Although all three process measures may be predictive of all three kinds of crime control, we speculate that certain social processes are more important for each kind of crime controller behavior. Each social process is a summation of multiple related items, and the three additive scales were statistically distinct from one another $(\alpha=.535)$.

First, relationality is defined as a dynamic state of social integration and kinship. We operationalized relationality by combining items related to intergenerational closure and community associations, choosing four items that together provide a measure of the extent of how the survey respondent relates to other community members. These items measure agreement (from 1 = strongly disagree through 5 = strongly agree) with the statements, "adults in this community know who the local children are," "there are adults in this community that children can look up to,” “parents in this community generally know each other," and "you can count on adults in this community to watch out that children are safe and don’t get into trouble.” These survey items were added together to collectively represent how survey respondents feel members of their community relate to one another $(\alpha=.799$, range $=4-20, M=14.52, S D=2.91)$. We suggest that this summed variable reflects the degree to which the survey respondent feels integrated with others in the neighborhood, speculating that when community members know one another and feel united in some way, intervention in crime becomes more likely.

Next, relativity was operationalized by combining survey items that measured the frequency of various neighboring activities. Relativity is defined as the fluid quality of how an individual is situated in their neighborhood; we use the occurrence of neighborly behaviors to capture the depth of community connectedness. Three questions measure the incidence (from 1 = never through 4 = often) of these behaviors, including "how often people in the community do favors for each other," "visit in each other's homes or on the street,” and “ask each other advice about personal things such as child rearing or job openings.” The 
summed scores for these items measure our concept of relativity, intended to reflect the degree to which the survey respondent feels connected to their community $(\alpha=.763$, range $=$ 3-12, $M=8.47, S D=1.85$ ). We propose that our measurement of relativity taps into the level at which the community resident feels embedded in the activities that occur in their neighborhood, hypothesizing that when individuals feel linked into the pulse of their community, they are more likely to observe and act in local crime problems.

Finally, responsibility is defined as the sense of duty an individual feels to contribute to his or her community's welfare. We operationalized this social process by combining ACCS items that tap into participants' motivational posturing regarding legitimacy of the law and a commitment to uphold it. Four items were selected that assess the duty of care that people feel. These survey questions measure the respondent's agreement (from $1=$ strongly disagree through 5 = strongly agree) with the assertions, "I obey the law with good will," "Obeying the police is the right thing to do," "I feel a strong commitment to help the police," and "I feel a moral obligation to obey the law." The values of these four items were summed to correspond with the respondent's feelings of personal obligation toward crime problems and community wellbeing $(\alpha=.774$ range $=4-20, M=16.68, S D=1.85)$. We built this variable to estimate the extent to which the individual may feel responsible for contributing to the wellbeing of their community, speculating that when a personal obligation toward lawfulness is felt, the community resident will be compelled to intervene in developing crime problems.

\section{Individual Characteristics}

A number of survey respondent characteristics were hypothesized to be related to the three crime control behaviors described above. Age $(M=51.27, S D=15.23)$ is significantly associated with offender handling $(F=18.348, p<.001)$, target guarding $(F=12.270, p<$ $.001)$, and place managing $(F=12.820, p<.001)$. Eight additional independent variables 
were included at the individual level of analysis (justified through confirmatory hypothesis testing), each of which was already a binary measure or was collapsed into two categories for theoretical and analytic purposes (in each case, a value of " 0 ” is the reference category). These variables include gender ( 1 = female, 59\%), foreign-born (1 = born in Australia, 72\%), marital status ( 1 = married, 67\%), dependent children $(1=$ has minor children living in the home, 38\%), education (1 = high school graduate or more, 55\%), home ownership (1 = owns home, $87 \%$ ), length of residence (1 = lived in same home five years or more, $77 \%$ ), and past victimization ( 1 = has been a victim of crime within the past twelve months, $16 \%$ ).

\section{Community Characteristics}

Drawing on the communities and crime literature, we acknowledge that dynamic crime control processes - relationality on handling, relativity on guarding, and responsibility on managing - will be influenced by structural neighborhood conditions. Accordingly, our study includes multilevel models in order to test whether community characteristics influence the relationship between individual characteristics and social processes and their impact on crime controller actions. Two variables are measured at the community level across the 148 Brisbane suburbs. First, the crime rate is measured as the logged average of the rate of total crime in a suburb from 2007 - 2009 as reported by the Queensland Police Service $(M=2.71, S D=.68)$. Second, the SEIFA (Socio-Economic Indexes for Areas) score represents the relative degree of disadvantage within a suburb, with higher scores corresponding with more affluent communities. The index of disadvantage for a suburb is calculated with information from 16 different variables (following a principal components analysis) measuring language, education, skills, employment, income, family structure, disability, and access to services. SEIFA scores are tabulated using data gathered by the Australian Bureau of Statistics (see Pink 2006), and are standardized to produce a mean score of 1,000 with a standard deviation of 100 ; the suburbs 
sampled for this study were just slightly more socio-economically advantaged than all Australian suburbs combined (range $=753-1154, M=1034.51, S D=81.86$ ).

\section{RESULTS}

In the first stage of the analyses, we performed six multivariate ordinal regressions (as each dependent variable in our models is the ordered projected likelihood of neighborhood intervention, from very unlikely to very likely). The coefficients represent the increase or decrease in the ordered log odds of being in a higher-level category of the dependent variable. For the six regression analyses, the first two models use the outcome of offender handling, the second two have a dependent variable of target guarding, and the final two predict place managing. In the first model of each of these dyads, individual characteristics are included; in the second model for each of the crime control outcomes, the measures of routine activity dynamics are included. The full results for each of these six models can be located in Table 1 .

Model 1 examines the influence of survey respondents' individual characteristics on their estimation that community members would engage in offender handling behaviors (doing something to disrupt truancy and youthful loitering in the neighborhood). Study participants who were older, female, married, had dependent children living at home, had a high school education or greater, are home owners, and had lived in their home for more than five years all indicated a greater belief that their neighbors would intervene as offender handlers (significant at $p<.05$ ). Contrarily, having personally experienced victimization within the past year was strongly negatively associated with offender handling projections ( $b$ $=-.424, p<.001)$. By including the three social process measures in Model 2, some of these individual characteristics reduce in magnitude and significance, although the general theme remains. In regard to the routine activity dynamics, both relationality $(b=.210, p<.001)$ and relativity $(b=.046, p<.01)$ were positively and significantly associated with the outcome of offender handling. The process measure of responsibility was not significant. Taken 
together, these two models demonstrate the importance of an individual's relationships and connectedness to their community in producing offender handling outcomes.

Model 3 uses the individual characteristics of study participants to predict their estimates of target guarding behaviors among members of their community (intervening in a mugging). Notably, home ownership ( $b=.450, p<.001$ ), length of residence $(b=.213, p<$ $.01)$ and being married $(b=.213, p<.01)$ were strong positive predictors of target guardianship. Contrarily, being a victim of crime was again negatively associated $(b=-.319$, $p<.001)$, while the influence of age switched direction from previous models $(b=-.008, p<$ .001) with older participants reporting lower estimations of target guarding. Once the process measures are included in Model 4 as predictors of target guarding, several variables reduce in magnitude and significance, although those that remain statistically significant maintain their direction of influence; worth noting is that the influence of prior victimization is reduced to non-significance. All three routine activity dynamics significantly and positively predicted target guarding, with the process of relationality $(b=.198, p<.001)$ reducing in strength from the previous model, but relativity $(b=.068, p<.001)$ and responsibility $(b=.060, p<$ .001) demonstrating larger coefficients. Summarily, Models 3 and 4 suggest that interpersonal relationships, community connectedness, and personal onus are again important for influencing target guardianship, with older ages and recent victimization detracting from the likelihood of intervention and home ownership encouraging guarding behavior.

Model 5 explores the impact of respondents’ individual characteristics on their estimations that fellow community members would engage in a place managing behavior (intervening in the development of an area brothel). Participants who were older, as well as females, those with dependent children living at home, and home owners reported an increased probability of place management intervention. Including the social process measures in Model 6 does not greatly change the individual-level relationships found in the previous model, although the variable of foreign-born becomes statistically significant $(b=$ - 
$.176, p<.05)$. In addition, the routine activity dynamics of relationality $(b=.136, p<.001)$ and responsibility $(b=.124, p<.001)$ were statistically significant and in the predicted direction, while relativity failed to reach significance at the $p=.05$ level $(b=.027)$. These findings indicate that both individual characteristics and a larger sense of community embeddedness and ownership over local crime problems are influential in a respondent's estimates of how likely their neighbors would be to engage in place management actions.

As graphically depicted in Figure 1d, we hypothesized that different social processes would be most important for different crime controller actions. While each process may be relevant for all types of crime prevention behaviors, we suggest that some factors matter more depending on the outcome. In comparing Models 2, 4, and 6 from Table 1, this hypothesis is moderately supported. As predicted, the coefficient for relationality is greatest for the offender handling model, relativity as a variable is highest for target guarding rather than for handling or managing, and responsibility is largest for the place managing dependent variable. The variable of relationality in particular is strongly and positively associated with all forms of crime control; however, responsibility was not predictive of offender handling, and relativity was not greatly influential over place managing. Although the models improve with the inclusion of the various social process measures, it is evident that there is still a large proportion of variation in the outcome variables left to be explained. We suggest that this provides confirmation of the importance of including community characteristics in the prediction of the likelihood of residents taking crime control action. Consequently, we estimated a multilevel model that included each suburb’s crime rate and relative approximation of social disadvantage; this information was added for each of the three estimations of crime controller actions. An overview of these models can be seen in Table 2 .

Model 1 of this multi-level series predicts the survey respondent's estimation that their neighbors would engage in offender handling with truanting and loitering youth. Age was positively associated with this outcome, while victimization was associated with a decreased 
probability of action when neighborhood crime rates and disadvantage are considered. Comparable to previous models, the routine activity dynamic of relationality was highly predictive of offender handling $(b=.183, p<.001)$, with relativity and responsibility both reaching statistical significance but with coefficients of a smaller magnitude. The suburb’s level of socioeconomic advantage was positively significantly associated with the action of offender handling, while the community’s crime rate was strongly and negatively influential. Survey respondents residing in suburbs with more crime were less likely to estimate that their neighbors would intervene in the case of truanting youth. Approximately $11 \%$ of the variance in the dependent variable could be attributed to differences between the suburbs, while the level-2 variables reduced the error in predicting offender handling by nearly $60 \%$.

Model 2 examines the compositional and contextual effects on the dependent variable of target guarding. Again, age was moderately, significantly, and negatively associated with the outcome; older respondents were less likely to expect that their neighbors would intervene in a mugging. Home ownership reversed direction and rose to significance from the previous model, with those owning their property reporting an increased estimation that fellow community members would engage in target guardianship. All three routine activity dynamics reached statistical significance $(p<.001)$. The inclusion of the level-2 variables revealed two notable relationships. First, the suburb’s crime rate and its association with target guardianship estimations reduced substantially in magnitude and significance, although the relationship remained negative. Second, neighborhoods that are more socioeconomically advantaged were significantly associated with increased predictions for target guarding. The model information reveals low levels of explained variance $\left(\rho=.052, \sigma^{2}=.039\right)$ until the level-2 covariates are included $(T=.602)$.

Model 3 explores the impact of individual characteristics, social processes, and community characteristics on the crime controller action of place managing (intervening in the development of a neighborhood brothel). Age was significantly predictive, but this time 
positively, with older respondents estimating a higher likelihood of place management among their neighbors. Female participants and those with dependent children also indicated increased probabilities of place managing. The process of relationality maintained its significance but decreased in magnitude; however, relativity reduced to non-significance and the routine activity dynamic of responsibility increased in influence $(b=.138, p<.001)$, indicating that expectations to help uphold the law and look after community wellness are associated with place management action. Finally, the inclusion of the community characteristics mirrored the trend from Model 2. The crime rate, although negative in direction, was not a significant predictor of place managing, yet the SEIFA score was $(\gamma=$ $.003, p<.001$ ), revealing that greater socioeconomic advantage in suburbs was associated with place management actions intended to reduce crime opportunities.

Overall, the multilevel ordered logistic regression models outlined in Table 2 reveal comparable relationships between the routine activity dynamics and predicted readiness for crime control action as were observed in Table 1: relationality is most predictive of offender handling, relativity as a social process variable is most influential in the target guarding model, and the responsibility item is most important for the place managing outcome. Again, the 3Rs are all relevant for all three types of crime control behaviors; however, in line with our hypothesis, there is moderate support for the idea that some of the social processes are more strongly paired with some types of crime control than others. We also find that certain individual characteristics and social dynamics enhance or stymie readiness for action to intervene in local crime problems. However, we further propose that, in accordance with the origins of routine activity theory (Cohen and Felson 1979), neighborhood features contribute to neighbors' willingness to intervene (somewhat supported by the moderate values obtained in the calculation of the level-2 proportionate reduction in error measures). Indeed, across all types of crime control action, more socially advantaged neighborhoods were more likely to report enhanced community intervention. Yet the crime rate was only significantly 
negatively associated with target guarding and offender handling, with this latter outcome (intervening with truanting and loitering youth) being heavily handicapped by area crime trends. Taken together, we reason that these findings provide initial evidence that context matters; individual characteristics, dynamic social processes, and neighborhood conditions variably influence different types of crime control action.

\section{DISCUSSION AND CONCLUSION}

The myriad of crime control programs and theories that focus on crime events and seek to reduce crime opportunities (e.g., crime prevention through environmental design, problem-oriented policing, situational crime prevention, environmental criminology and crime analysis) tend to emphasize immediate and measurable pre-post differences in intervention and outcome. Oftentimes, little interest is paid to the mechanisms and dynamic processes that facilitate an observed reduction in crime or disorder (for an exception, see Tilley 2009). Crime control research identifies specific intervention manipulations, such as the introduction of target hardening measures, the redressing of broken windows, or the leveraged participation of offender handlers or the managers of problematic places (Braga and Weisburd 2010; Eck et al. 2010; Eck and Wartell 1998; Madensen 2007; Mazerolle, Kadleck, and Roehl 1998; Tillyer 2008; Welsh, Mudge, and Farrington 2010). Yet these efforts explain why victimization or crime decreases rather than how.

This paper sought to better understand routine activity theory (RAT) by explicating three unique crime prevention mechanisms - relationality, relativity, and responsibility - that influence variable crime control actions. We examined the influences of these "3Rs" while theoretically and empirically revisiting how macro variations in crime opportunities contextualize these crime prevention mechanisms. Using the Australian Community Capacity Study (ACCS), we assess how the routine activity dynamics explain variations in crime control action. In terms of these 3Rs and their influence on readiness for intervention, 
we identify three main findings. First, we find that both relationality and relativity are positively and significantly associated with offender handling, demonstrating the importance of an individual's relationships and connectedness to their community for handling actions that limit prospective offenders' access to crime opportunities. Second, we show that interpersonal relationships, community connectedness, and a persons’ sense of responsibility are important for influencing target guardianship. Third, a person's larger sense of community embeddedness and ideas about ownership over local crime problems influences how likely they think their neighbors are to engage in place management actions. We see a general trend that all three routine activity dynamics matter for the three types of crime control action; however, overall, as predicted, we find that relationality is greatest for offender handling, relativity is highest for target guarding, and responsibility is largest for place managing. Put differently, we observed that relationality is most influential in the offender handling model, relativity matters most in the target guarding model, and responsibility is strongest as a predictor within the place management model.

Our paper also shows that it may be fruitful to revisit the original presentation of routine activity theory. Although the crime triangle dyads - pairing offenders with handlers, targets with guardians, and places with managers - make crime events seem easily avoided (i.e., as simple as adding an effective controller to interrupt the merger of the crime event elements), we recognize the influence of larger community conditions that impact controller availability and action. Neighborhood conditions direct the social processes that take place therein, which then ready or hinder prospective crime controllers toward intervening with crime opportunities. Prospective crime controllers may already be present, but the question of whether they are engaged with the potential crime problem (whether they notice, whether they are motivated to intervene, which route of action they will take, when they will act, and so forth) may be a matter of context (Reynald, 2011a). As an illustration, our analyses demonstrated that a suburb’s crime rate was linearly unrelated to place management action. 
We speculate that for some residents, high rates of crime may motivate them to do something to stymie the development of further crime, while for other residents, high levels of crime may produce helplessness or indifference and then inaction. Hence, community conditions shape the social processes that then facilitate the activation and degree of crime control. As initially demonstrated by Cohen and Felson (1979), social-structural conditions influence collective perceptions and symbolic processes that are important for crime control action (Sampson, 2013). In examining a community’s capacity to engage in different forms of crime opportunity disruption (minimizing pursuit, enhancing risks, and reducing availability; see Figure 2), we likewise find evidence that neighborhood features and dynamic social routines are important.

Notwithstanding our interesting findings, our paper is not without limitations. First, we have not addressed the influence of individual motivations, either theoretically or empirically. The ACCS survey does not ask about the specific motivations for why people take the actions they do, focusing instead on the different routes participants pursue to address crime and disorder (e.g., contacting city council versus phoning the police). Second, we recognize that the ACCS questions were not designed, from the outset, to measure the routine activity dynamics that we have modeled in this paper. Whilst we make a strong case for why these measures make both theoretical and empirical sense, we recognize that there may be better ways to operationalize the 3R constructs outside the constraints of these secondary data. We hope that this initial modest test prompts empirical inquiries that further explore our typology of the social processes of crime control. Third, the Australian data from the City of Brisbane is limited in terms of its generalizability to other countries and cities around the world. However, although our study is not a perfect test of our theoretical extension of RAT, there is sufficient evidence to suggest that there are different forms of crime control action, and that individual factors, social processes, and community characteristics are variably associated with each type. 
One of our central goals of this paper was to bring a greater theoretical understanding around the processes of crime control than what we currently know from the extant literature. We conclude that offender handling, target guarding, and place managing are different outcomes, operate through different social processes, and that these associations do not unfold in a vacuum. Rather, these dynamics are deeply embedded within the social fabric of communities, and as such, individual actions are influenced by these contexts. Moreover, crime control processes vary, but not on a present-absent dichotomy as is often articulated in many studies of routine activity theory. Alternatively, our study finds that these 3Rs vary on a continuum and according to different types of crime opportunities. We suggest the importance of paying attention to the macro context originally espoused in RAT and the need to develop a deeper theoretical appreciation for the various social processes that trigger these different crime control actions. 


\section{REFERENCES}

Akers, R.L. (1998) Social Learning and Social Structure: A General Theory of Crime and Deviance. Boston: Northeastern University Press.

Bellair, P. (1997) Social interaction and community crime: examining the importance of neighbor networks. Criminology 35(4): 677-703.

Bernber, J.G. and Krohn, M.D. (2003) Labeling, life chances, and adult crime: the direct and indirect effects of official intervention in adolescence on crime in early adulthood. Criminology 41(4): 1287-1318.

Braga, A.A. and Weisburd, D.L. (2010) Policing Problem Places: Crime Hot Spots and Effective Prevention. New York: Oxford University Press.

Brown, B.B., Perkins, D.D. and Brown, G. (2004) Incivilities, place attachment and crime: block and individual effects. Journal of Environmental Psychology 24(3): 359-371.

Browning, C.R. (2009) Illuminating the downside of social capital: negotiated coexistence, property crime, and disorder in urban neighborhoods. American Behavioral Scientist 52(11): 1556-1578.

Browning, C.R., Feinberg, S.L. and Dietz, R.D. (2004) The paradox of social organization: networks, collective efficacy, and violent crime in urban neighborhoods. Social Forces 83(2): 503-534.

Bursik Jr, R.J. (1999) The informal control of crime through neighborhood networks. Sociological Focus 32(1): 85-97.

Bursik Jr, R. J. (2000) The systemic theory of neighborhood crime rates. In: S. Simpson (ed.) Of Crime and Criminality. Thousand Oaks, CA: Pine Forge Press, pp. 87-103

Bursik Jr, R.J. and Grasmick, H.B. (1993) Neighborhoods and Crime: The Dimensions of Effective Community Control. New York: Macmillan.

Clarke, R.V. 1992 Situational Crime Prevention: Successful Case Studies. Albany, NY: Harrow and Heston. 
Clarke, R.V. (1997) Situational Crime Prevention: Successful Case Studies, Vol. 2. Monsey, NY: Criminal Justice Press.

Clarke, R.V. (2008) Situational crime prevention. In: R. Wortley and L. Mazerolle (eds.) Environmental Criminology and Crime Analysis. Cullumpton, UK: Willan, pp. 48-69.

Clarke, R.V. (2012) Opportunity makes the thief. Really? And so what? Crime Science 1(1): $1-9$.

Clarke, R.V. and Eck, J.E. (2005) Crime Analysis for Problem Solvers in 60 Small Steps. Washington, DC: Office of Community Oriented Policing Services, U.S. Department of Justice.

Clarke, R.V. and Mayhew, P. (1998) Preventing crime in parking lots. In: M. Felson and R. Peiser (eds.) Reducing Crime through Real Estate Development and Management. Washington, DC: Urban Land Institute, pp. 125-136.

Cohen, L.E. and Felson, M. (1979) Social change and crime trends: a routine activity approach. American Sociological Review 44(4): 588-608.

Cornish, D.B. and Clarke, R.V. (1986) The Reasoning Criminal: Rational Choice Perspectives on Criminal Offending. New York: Springer-Verlag.

Cornish, D.B. and Clarke, R.V. (2003) Opportunities, precipitators and criminal decisions: a reply to Wortley’s critique of situational crime prevention. Crime Prevention Studies 16: 41-96.

Cullen, F.T. (1994) Social support as an organizing concept for criminology: presidential address to the Academy of Criminal Justice Sciences. Justice Quarterly 11(4): 527-59.

Eck, J.E. (1994) Drug markets and drug places: a case-control study of the spatial structure of illicit drug dealing. PhD dissertation, University of Maryland, College Park.

Eck, J.E. (2003) Police problems: the complexity of problem theory, research and evaluation. Crime Prevention Studies 15: 67-102. 
Eck, J.E. and Clarke, R. V. (2003) Classifying common police problems: a routine activity theory approach. Crime Prevention Studies 16: 7-39.

Eck, J.E., Madensen, T., Payne, T., Wilcox, P., Fisher, B.S. and Scherer, H. (2010) Situational Crime Prevention at Specific Locations in Community Context: Place and Neighborhood Effects. Washington, DC: U.S. Department of Justice.

Eck, J.E. and Wartell, J. (1998) Improving the management of rental properties with drug problems: a randomized experiment. Crime Prevention Studies 9: 161-185.

Eck, J.E. and Weisburd, D. (1995) Crime places in crime theory. Crime Prevention Studies 4:1-33.

Ekblom, P. (1994) Proximal circumstances: a mechanism-based classification of crime prevention. Crime Prevention Studies 2: 185-232.

Ekblom, P. (2005) How to police the future: scanning for scientific and technological innovations which generate potential threats and opportunities in crime, policing and crime reduction. In: M.J. Smith and N. Tilley (eds.) Crime Science: New Approaches to Preventing and Detecting Crime. Cullompton, UK: Willan, pp. 27-55.

Farrell, G. and Pease, K. (2007) Preventing repeat residential burglary victimization. In: B.C. Welsh and D.P. Farrington (eds.) Preventing Crime: What Works for Children, Offenders, Victims, and Places. New York: Springer, pp. 161-176.

Farrell, G., Phillips, C. and Pease, K. (1995) Like taking candy: why does repeat victimization occur? British Journal of Criminology 35(3): 384-399.

Felson, M. (1986) linking criminal choices, routine activities, informal control, and criminal outcomes. In: D.B. Cornish and R.V. Clarke (eds.) The Reasoning Criminal: Rational Choice Perspectives on Offending. New York: Springer-Verlag, pp. 119-128.

Felson, M. (1995) Those who discourage crime. Crime Prevention Studies 4: 53-66.

Felson, M. (2008) Routine activity approach. In: R. Wortley and L. Mazzerole (eds) Environmental Criminology and Crime Analysis. Cullumpton, UK: Willan, pp. 70-77. 
Felson, M., and Clarke, R.V. (1998) Opportunity Makes the Thief: Practical Theory for Crime Prevention. London: Home Office.

Garofalo, J., Siegel, L. and Laub, J. (1987) School-related victimizations among adolescents: an analysis of National Crime Survey (NCS) narratives. Journal of Quantitative Criminology 3(4): 321-338.

Goldstein, H. (1979) Improving policing: a problem-oriented approach. Crime \& Delinquency 25(2): 236-258.

Goldstein, H. (1990) Problem-Oriented Policing. Philadelphia: Temple University Press.

Goudriaan, H., Wittebrood, K. and Nieuwbeerta, P. (2006) Neighborhood characteristics and reporting crime: effects of social cohesion, confidence in police effectiveness and socio-economic disadvantage. British Journal of Criminology 46(4): 719-742.

Groff, E.R. (2007) Simulation for theory testing and experimentation: an example using routine activity theory and street robbery. Journal of Quantitative Criminology 23(2): 75-103.

Hirschfield, A. and Bowers, K.J. (1997) The effect of social cohesion on levels of recorded crime in disadvantaged areas. Urban Studies 34(8): 1275-1295.

Hirschi, T. (1969) Causes of Delinquency. Berkeley: University of California Press.

Hollis-Peel, M.E., Reynald, D.M., van Bavel, M., Elffers, H. and Welsh, B.C. (2011) Guardianship for crime prevention: a critical review of the literature. Crime, Law and Social Change 56(1): 53-70.

Hollis-Peel, M.E., Reynald, D.M. and Welsh, B.C. (2012) Guardianship and crime: an international comparative study of guardianship in action. Crime, Law and Social Change 58(1): 1-14.

Hunter, R.D. and Jeffrey, C.R. (1997) Preventing convenience store robbery through environmental design. In: R.V. Clarke (ed.) Situational Crime Prevention: Successful Case Studies. Monsey, NY: Criminal Justice Press, pp. 191-199. 
Jeffery, C.R. (1971) Crime Prevention through Environmental Design. Beverly Hills, CA: Sage.

Kelling, G.L. and Wilson, J.Q. (1982) Broken windows: the police and neighborhood safety. The Atlantic 249(3): 29-38.

La Vigne, N. (1994) Rational choice and inmate disputes over phone use on Rikers Island. Crime Prevention Studies 3: 109-125.

Lambert, E.G., Jaishankar, K., Jiang, S., Pasupuleti, S. and Bhimarasetty, J.V. (2011) Correlates of formal and informal social control on crime prevention: an exploratory study among university students. Asian Criminology 7(3): 239-250.

Lasley, J. (1998) “Designing Out” Gang Homicides and Street Assaults. Washington, DC: U.S. Department of Justice.

Laycock, G. and Tilley, N. (1995) Implementing crime prevention. Crime and Justice 19: 535-584.

Lilly, J.R., Cullen, F.R. and Ball, R.A. (2007) Criminological Theory: Context and Consequences, $4^{\text {th }}$ ed. Thousand Oaks, CA: Sage.

Lynch, J.P. (1987) Routine activity and victimization at work. Journal of Quantitative Criminology 3(4): 283-300.

Madensen, T.D. (2007) Bar management and crime: toward a dynamic theory of place management and crime hotspots. PhD dissertation, University of Cincinnati.

Mazerolle, L.G., Kadleck, C. and Roehl, J. (1998) Controlling drug and disorder problems: the role of place managers. Criminology 36(2): 371-404.

Mazerolle, L., Wickes, R., Cherney, A., Murphy, K., Sargeant, E. and Zahnow, R. (2012) Community Variations in Crime: A Spatial and Ecometric Analysis, Wave 3: Technical Report No. 1, Study Methods and Basic Statistics. Brisbane: Australian Research Council. 
Mazerolle, L., Wickes, R. and McBroom, J. (2010) Community variations in violence: the role of social ties and collective efficacy in comparative context. Journal of Research in Crime and Delinquency 47(1): 3-30.

Morenoff, J.D., Sampson, R.J. and Raudenbush, S.W. (2001) Neighborhood inequality, collective efficacy, and the spatial dynamics of urban violence. Criminology 39(3): 517-558.

Mustaine, E.E. and Tewksbury, R. (1999) A routine activity theory explanation for women’s stalking victimizations. Violence Against Women 5(1): 43-62.

Newman, O. (1973) Defensible Space, People and Design in the Violent City. London: Architectural Press.

Osgood, D.W., Wilson, J.K., O’Malley, P.M., Bachman, J.G. and Johnston, L.D. (1996) Routine activities and individual deviant behavior. American Sociological Review 61(4): 635-655.

Painter, K. and Tilley, N. (1999) Surveillance of Public Space: CCTV, Street Lighting and Crime Prevention. Monsey, NY: Criminal Justice Press.

Pattillo, M.E. (1998) Sweet mothers and gangbangers: managing crime in a middle class neighborhood. Social Forces 76(3): 747-774.

Pawson, R. and Tilley, N. (1997) Realistic Evaluation. London: Sage.

Perkins, D.D., Florin, P., Rich, R.C., Wandersman, A. and Chavis, D.M. (1990) Participation and the social and physical environment of residential blocks: crime and community context. American Journal of Community Psychology 18(1): 83-115.

Pink, B. (2008) Information Paper: An Introduction to Socio-Economic Indexes for Areas (SEIFA). Canberra: Australian Bureau of Statistics.

Rankin, J.H. and Wells, L.E. (1990) The effect of parental attachments and direct controls on delinquency. Journal of Research on Crime and Delinquency 27(2): 140-165. 
Raudenbush, S.W., Spybrook, J. Congdon, R., Liu, X. and Martinez, A. (2011) Optimal Design Software for Multi-Level and Longitudinal Research (Version 3.01). Available from www.wtgrantfoundation.org.

Reynald, D.M. (2009) Guardianship in action: developing a new tool for measurement. Crime Prevention \& Community Safety 11(1): 1-20.

Reynald, D.M. (2010) Guardians on guardianship: factors affecting the willingness to supervise, the ability to detect potential offenders, and the willingness to intervene. Journal of Research in Crime and Delinquency 47(3): 358-390.

Reynald, D.M. (2011a) Guarding Against Crime: Measuring Guardianship within Routine Activity Theory. Burlington, VT: Ashgate.

Reynald, D.M. (2011b) Factors associated with the guardianship of places: assessing the relative importance of the spatio-physical and sociodemographic contexts in generating opportunities for guardianship. Journal of Research in Crime and Delinquency 48(1): 110-142.

Ross, C.E. and Jang, S.J. (2000) Neighborhood disorder, fear, and mistrust: the buffering role of social ties with neighbors. American Journal of Community Psychology 28(4): 401420.

Sampson, R., Eck, J.E. and Dunham, J. (2010) Super controllers and crime prevention: a routine activity explanation of crime prevention success and failure. Security Journal 23(1): 37-51.

Sampson, R.J. (1986) Crime in cities: the effects of formal and informal social control. Crime and Justice 8: 271-311.

Sampson, R.J. (2008) Collective efficacy theory: lessons learned and directions for future inquiry. In: F.T. Cullen, J.P. Wright and K.R. Blevins (eds) Taking Stock: The Status of Criminological Theory. New Brunswick, NJ: Transaction, pp. 35-59. 
Sampson, R.J. (2013) The place of context: a theory and strategy for criminology's hard problems. Criminology 51(1): 1-31.

Sampson, R.J., and Groves, W.B. (1989) Community structure and crime: testing socialdisorganization theory. American Journal of Sociology 94(4): 774-802.

Sampson, R.J., Morenoff, J.D. and Earls, F. (1999) Beyond social capital: spatial dynamics of collective efficacy for children. American Sociological Review 64(5): 633:60.

Sampson, R.J., Morenoff, J.D. and Gannon-Rowley, T. (2002) Assessing neighborhood effects: social processes and new directions in research. Annual Review of Sociology 28(1): 443-478.

Sampson, R., Raudenbush, S.W. and Earls, F. (1997) Neighborhoods and violent crime: a multilevel study of collective efficacy. Science 277(5328): 918-924.

Shearing, C. and Stenning, P. (1992) From the panopticon to Disney World: the development of discipline. In: R.V. Clarke (ed.) Situational Crime Prevention: Successful Case Studies. Monsey, NY: Criminal Justice Press, pp. 300-304.

Sherman, L.W., Gartin, P.R. and Buerger, M.E. (1989) Hot spots of predatory crime: routine activities and the criminology of place. Criminology 27(1): 27-56.

Sloan-Howitt, M. and Kelling, G. (1992) Subway graffiti in New York City: 'gettin’ up’ vs. ‘meanin’ it and cleanin’ it.’ In: R.V. Clarke (ed.) Situational Crime Prevention: Successful Case Studies. Monsey, NY: Criminal Justice Press, pp. 239-248.

Sousa, W.H. and Kelling, G.L. (2006) Of broken windows, criminology, and criminal justice. In: D. Weisburd and A. Braga (eds.) Police Innovation: Contrasting Perspectives. Cambridge, MA: Cambridge University Press, pp. 77-97.

Sutherland, E.H. (1947) Principles of Criminology, $4^{\text {th }}$ ed. Philadelphia: Lippincott. Taylor, R.B., Gottfredson, S.D., and Brower, S. (1984) Block crime and fear: defensible space, local social ties, and territorial functioning. Journal of Research in Crime and Delinquency 21(4): 303-331. 
Tilley, N. (1993) After Kirkholt: theory, method and results of replication evaluations (Police Research Group Crime Prevention Unit Series Paper No. 47). London: Home Office Police Department.

Tilley, N. (2009) Crime Prevention. New York: Willan.

Tillyer, M.S. (2008) Getting a handle on street violence: using environment criminology to understand and prevent repeat offender problems. PhD dissertation, University of Cincinnati.

Tseloni, A., WIttebrood, K., Farrell, G. and Pease, K. (2004) Burglary victimization in England and Wales, the United States and the Netherlands: A cross-national comparative test of routine activities and lifestyle theories. British Journal of Criminology 44(1): 66-91.

van Wilsem, J., Wittebrood, K. and de Graaf, N.D. (2006) Socioeconomic dynamics of neighborhoods and the risk of crime victimization: a multilevel study of improving, declining, and stable areas in the Netherlands. Social Problems 53(2): 226-247.

Warner, B.D. (2003) The role of attenuated culture in social disorganization theory. Criminology 41(1): 73-97.

Warner, B.D. (2007) Directly intervene or call the authorities? A study of forms of neighborhood social control within a social disorganization framework. Criminology 45(1): 99-129.

Warner, B.D. and Wilcox Rountree, P. (1997) Local social ties in a community and crime model: questioning the systemic nature of informal social control. Social Problems 44(4): 520-36.

Weisburd, D. and Eck, J. (2004) What can police do to reduce crime, disorder, and fear? Annals of the American Academy of Political and Social Science 593(1): 43-65. 
Weisburd, D. (2012) Bringing social context back into the equation: the importance of social characteristics of places in the prevention of crime. Criminology \& Public Policy 11(2): 317-326.

Wells, L.E. and Rankin, J.H. (1998) Direct parental controls and delinquency. Criminology 26(2): 263-285.

Welsh, B.C., Mudge, M.E. and Farrington, D.P. (2010) Reconceptualizing public area surveillance and crime prevention: security guards, place managers and defensible space. Security Journal 23(4): 299-319.

Wickes, R., Hipp, J.R., Sargeant, E. and Homel, R. (2013) Collective efficacy as a task specific process: examining the relationship between social ties, neighborhood cohesion and the capacity to respond to violence, delinquency and civic problems. American Journal of Community Psychology 52(1): 115-127.

Wilcox Rountree, P. and Land, K.C. (1996) Burglary victimization, perceptions of crime risk, and routine activities: a multilevel analysis across Seattle neighborhoods and census tracts. Journal of Research in Crime and Delinquency 33(2): 147-180.

Wilcox, P., Madensen, T.D. and Tillyer, M.S. (2007) Guardianship in context: implications for burglary victimization risk and prevention. Criminology 45(4): 771-803.

Wilkinson, D.L. (2007) Local social ties and willingness to intervene: textured views among violent urban youth of neighborhood social control dynamics and situations. Justice Quarterly 24(2): 185-220.

Wortley, R. (2001) A classification of techniques for controlling situational precipitators of crime. Security Journal 14(4): 63-82.

Xie, M. and McDowall, D. (2008) The effects of residential turnover on household victimization. Criminology 46(3): 539-575. 

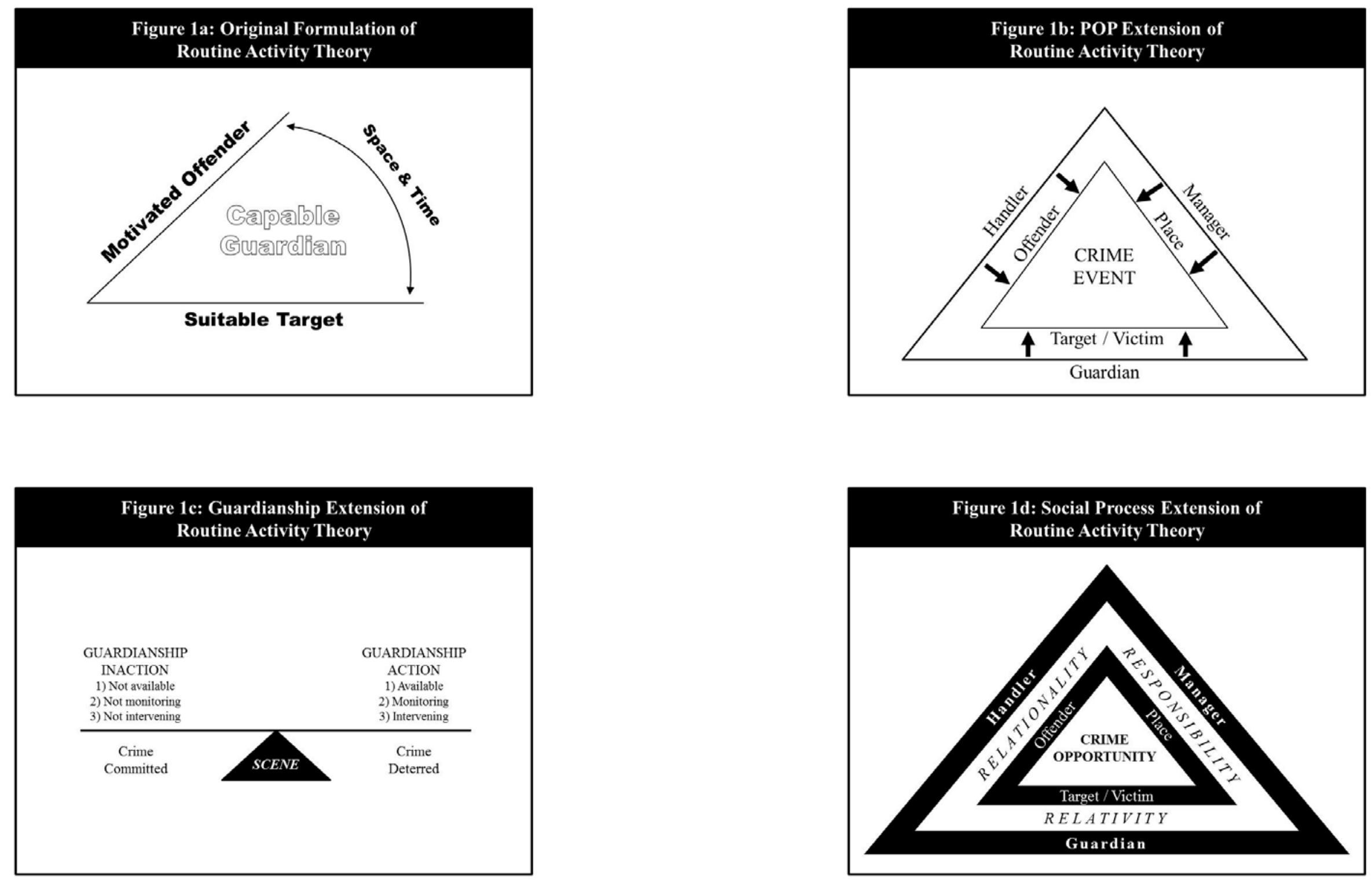


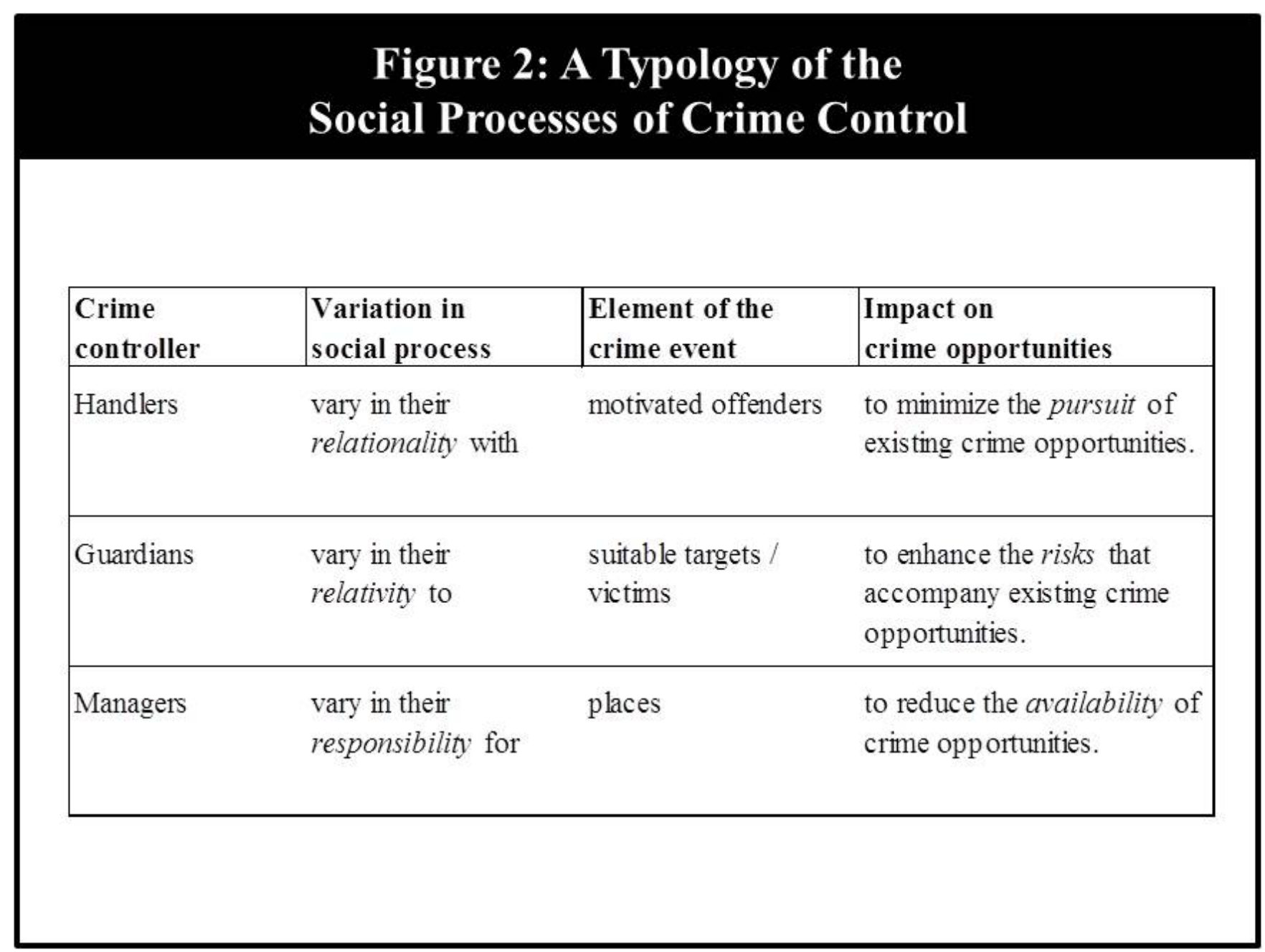


Table 1: Multivariate Ordinal Regression Predicting Readiness for Crime Control Action

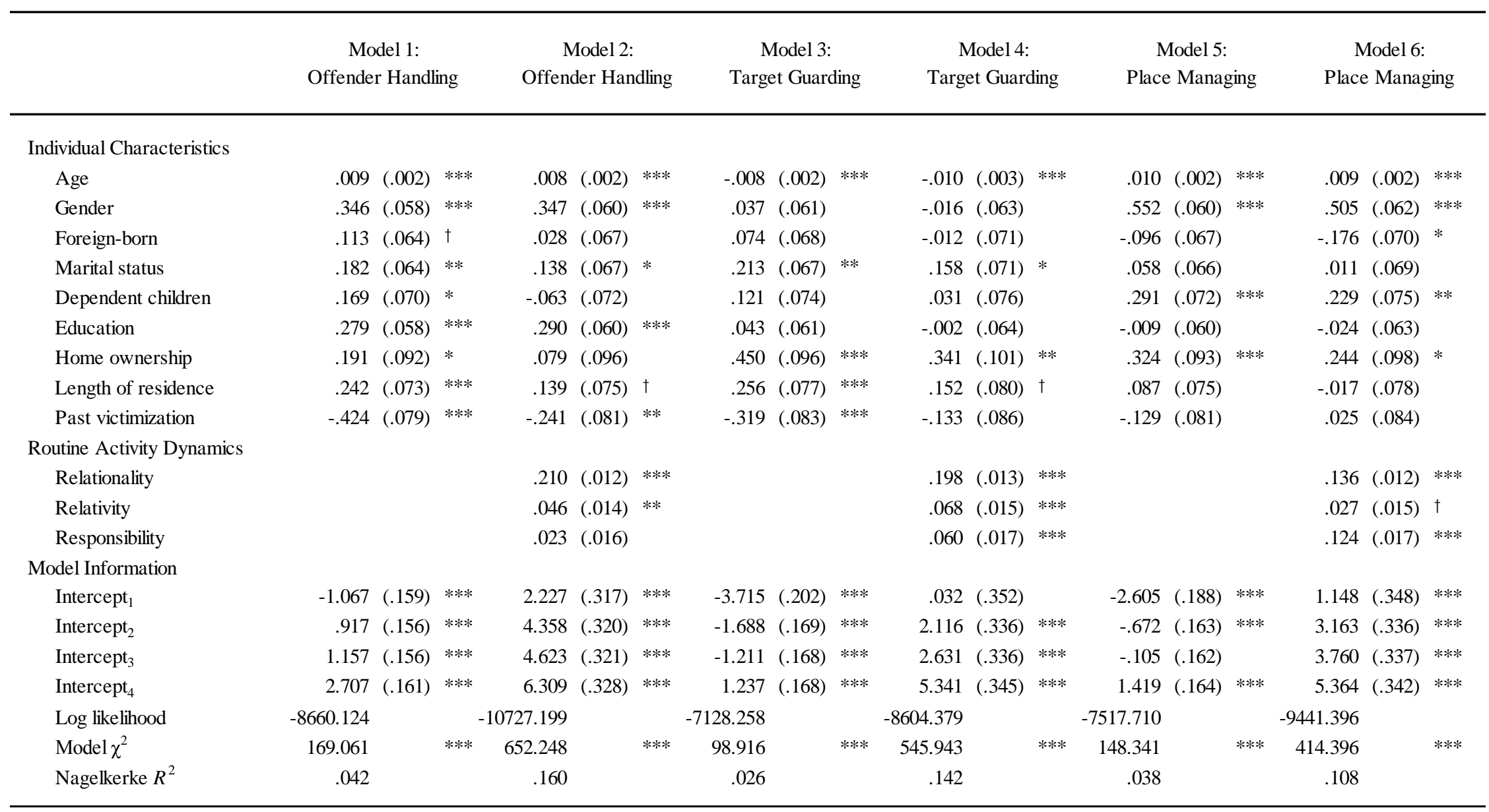

$\dagger p<.10 ; * p<.05 ; * * p<.01 ; * * * p<.001$ 
Table 2: Multilevel Mixed-Effects Ordinal Regression Predicting Readiness for Crime Control Action

\begin{tabular}{|c|c|c|c|c|c|c|c|c|c|}
\hline Individual Characteristics & \multicolumn{3}{|c|}{$\begin{array}{c}\text { Model 1: } \\
\text { Offender Handling }\end{array}$} & \multicolumn{3}{|c|}{$\begin{array}{c}\text { Model 2: } \\
\text { Target Guarding }\end{array}$} & \multicolumn{3}{|c|}{$\begin{array}{c}\text { Model 3: } \\
\text { Place Managing }\end{array}$} \\
\hline Age & .009 & $(.002)$ & $* * *$ & -.010 & $(.003)$ & $* * *$ & .009 & $(.003)$ & $* * *$ \\
\hline Gender & .363 & $(.061)$ & $* * *$ & -.015 & $(.064)$ & & .520 & $(.063)$ & $* * *$ \\
\hline Foreign-born & .001 & $(.069)$ & & -.026 & $(.072$ & & -.170 & $(.072)$ & $*$ \\
\hline Marital status & .058 & $(.069)$ & & .096 & $(.072)$ & & -.058 & $(.072)$ & \\
\hline Dependent children & .102 & $(.073)$ & & .042 & $(.076)$ & & .225 & $(.076)$ & $* *$ \\
\hline Education & .181 & $(.062)$ & $* *$ & -.069 & $(.065)$ & & -.104 & $(.065)$ & \\
\hline Home ownership & -.047 & $(.098)$ & & .236 & $(.103)$ & $*$ & .130 & $(.101)$ & \\
\hline Length of residence & .109 & $(.076)$ & & .140 & $(.080)$ & $\dagger$ & -.018 & $(.080)$ & \\
\hline Past victimization & -.148 & $(.083)$ & $\dagger$ & -.088 & $(.088)$ & & .071 & $(.086)$ & \\
\hline \multicolumn{10}{|l|}{ Routine Activity Dynamics } \\
\hline Relationality & .183 & $(.013)$ & $* * *$ & .179 & $(.013)$ & $* * *$ & .117 & $(.013)$ & $* * *$ \\
\hline Relativity & .042 & $(.014)$ & $* *$ & .070 & $(.015)$ & $* * *$ & .026 & $(.015)$ & $\dagger$ \\
\hline Responsibility & .039 & $(.017)$ & $*$ & .067 & $(.017)$ & $* * *$ & .138 & $(.018)$ & $* * *$ \\
\hline \multicolumn{10}{|l|}{ Community Characteristics } \\
\hline Crime rate & -.379 & $(.069)$ & $* * *$ & -.133 & $(.057)$ & $*$ & -.108 & $(.071)$ & \\
\hline SEIFA score & .003 & $(.001)$ & $* * *$ & .002 & $(.000)$ & $* * *$ & .003 & $(.001)$ & $* * *$ \\
\hline \multicolumn{10}{|l|}{ Model Information } \\
\hline Intercept $_{1}$ & 3.324 & $(.756)$ & $* * *$ & 1.841 & $(.641)$ & $* *$ & 3.765 & $(.769)$ & $* * *$ \\
\hline Intercept $_{2}$ & 5.513 & $(.759)$ & $* * *$ & 3.938 & $(.635)$ & $* * *$ & 5.799 & $(.765)$ & $* * *$ \\
\hline Intercept $_{3}$ & 5.792 & $(.759)$ & $* * *$ & 4.454 & $(.635)$ & $* * *$ & 6.411 & $(.766)$ & $* * *$ \\
\hline Intercept $_{4}$ & 7.555 & $(.763)$ & $* * *$ & 7.190 & $(.643)$ & $* * *$ & 8.067 & $(.771)$ & $* * *$ \\
\hline Log likelihood & -5288.529 & & & -4277.887 & & & -4675.3022 & & \\
\hline Wald $\chi^{2}$ & 605.59 & & $* * *$ & 560.08 & & $* * *$ & 407.58 & & $* * *$ \\
\hline Likelihood-ratio test & 26.86 & & $* * *$ & 0.95 & & & 17.27 & & $* * *$ \\
\hline$\rho$ (Intra-class correlation coefficient) & .111 & & & .052 & & & .066 & & \\
\hline$\sigma^{2}($ Level-1 PRE) & .049 & & & .039 & & & .021 & & \\
\hline$T$ (Level-2 PRE) & .598 & & & .602 & & & .488 & & \\
\hline
\end{tabular}

$\dagger p<.10 ;{ }^{*} p<.05 ;{ }^{* *} p<.01 ;{ }^{* * *} p<.001$ 
Lacey Schaefer is a Lecturer in the School of Criminology and Criminal Justice at Griffith University. She received her doctorate from the University of Cincinnati where her dissertation applied the concepts of environmental criminology and opportunity reduction to probation and parole supervision. Her current research examines criminological theory, correctional interventions and desistance, and community-level crime prevention factors.

Lorraine Mazerolle is a Research Professor in the Institute for Social Science Research (ISSR) at the University of Queensland and an Australian Research Council (ARC) Laureate Fellow. She is the recipient of numerous US and Australian national competitive research grants and winner of the Joan McCord Award and Freda Adler Prize. Professor Mazerolle is a Fellow and past president of the Academy of Experimental Criminology, Chair of the American Society of Criminology Division of Experimental Criminology and author of scholarly books and articles on policing, drug law enforcement, third party policing, regulatory crime control, displacement of crime, and crime prevention. 